\title{
Identificação territorial, identificação étnica em Cartagena, Colômbia
}

\author{
Elisabeth Cunin
}

\section{Resumo}

Neste texto, o propósito é discutir os processos de identificação socioespacial por meio do estudo da qualificação étnico-racial diferencial dos espaços e dos habitantes da cidade de Cartagena, na Colômbia. Consiste na análise dos mecanismos de produção recíproca dos territórios e das identidades, reveladores das formas de relação com o outro e portadores das aspirações à cidadania e à citadinidade. São abordados três casos particulares: a significação da imagem de "cidade mestiça" tradicionalmente atribuída a Cartagena; as múltiplas interpretaçôes referentes à erradicação, no início da década de 1970, do bairro Chambacú, situado na entrada da cidade histórica e turística; os modos de apropriação territorial pelos habitantes que fazem valer suas origens étnicas, no contexto de afirmação do multiculturalismo dos anos 1990.

Palavras-chave: territórios urbanos, identidades urbanas, alteridade, pertencimento racial, cidadania; citadinidade; territorizalização; processos de identificação situacionais e interacionais.

\section{Abstract}

\section{Territorial and ethnic identification in Cartagena (Colombia)}

The main purpose of this article is to discuss the social-spatial processes of identification through the study of different ethnic-racial qualification of spaces and inhabitants of the city of Cartagena, Colombia. It consists on the analysis of the reciprocal reproduction mechanisms of the territories and the identities, revealing forms of relation with the other one and carriers of the citizenship aspirations and belonging to the city. Three particular cases are discussed: the 
significance of the "mestizo cross-bred city" image, traditionally attributed to Cartagena; the multiple interpretations referring to eradication, in the beginning of the 1970's decade, of the neighborhood of Chambacú, situated on the entrance of the tourist and historic city; and the ways of the territorial appropriation by inhabitants that make the most of their ethnic identity in the context of the multiculturalism affirmations during the 1990s.

Keywords: urban territories, urban identities, racial belonging, citizenship and city belonging, otherness (alterity), territorialization, interaction and situational processes of identity, Cartagena, Colombia.

\section{Résumé}

\section{Identification territoriale, identification ethnique à Carthagène (Colombie)}

Cet article propose de s'interroger sur les processus d'identification socio-spatiale à travers l'étude de la qualification ethnique-raciale différentielle des espaces et des habitants de la ville de Cartagena, en Colombie. Il s'agit d'étudier les mécanismes de la production réciproque des territoires et des identités, révélateurs des formes de la relation à l'autre et porteurs des aspirations à la citoyenneté et à la citadinité (comme l'appartenance à la ville). Je m’intéresserai à trois cas particuliers: la signification de l'image de "ville métisse» traditionnellement associée à Cartagena; les interprétations multiples portant sur l'éradication d'un quartier, Chambacú, situé à l'entrée de la ville historique et touristique, au début des années 1970; les modes d'appropriation territoriale par des habitants se réclamant de leur appartenance ethnique, dans le contexte d'affirmation du multiculturalisme des années 1990.

Mots-clés: territoires urbaines, identités urbaines, altérité, appartenance racial, citoyenneté, citadinité (comme l'appartenance à la ville), territorialisation, processus d'identification situationnels et interactionnels, Carthagène, Colombie. 
Q uem faz pesquisas sobre Cartagena vê-se diante de uma ambigüidade: a observação mostra de imediato que, à medida que se desce na escala socioeconômica, a população é mais negra; que os bairros com baixo nível de urbanidade têm os moradores de pele mais escura. Mas, paradoxalmente, é dificílimo expressar essa segregação sócio-espacial em termos étnicos. Exemplo evidente é o que se depreende dos estudos realizados no departamento de Trabajo social da Universidade de Cartagena: cada ano, para obter o diploma, os estudantes devem fazer a monografia de um bairro. Ora, nessas monografias, em que os elementos de estruturação e de segregação socioeconômicos são analisados pormenorizadamente, em que a concentração da pobreza, do subemprego e da ausência de educação é reconhecida e denunciada, a dimensão racial nunca é mencionada, nem na caracterização da população, nem na explicitação das causalidades. Trata-se de "bairros populares", não de "bairros étnicos".

De fato, a questão que aparece em Cartagena, em particular após a instauração do multiculturalismo, é a da identificação e definição das "populações negras". Alguém é "negro" por designação categorial externa? E, se assim for, quais os critérios dessa designação? Aparência física, definição a priori (traços culturais, o fato de pertencer a um território), genealogia? Por auto-identificação? Mas, ao agir dessa forma, não estará o pesquisador reproduzindo estratégias, conscientes ou inconscientes, de instrumentalização ou de ocultação, das quais precisamente compete a ele descobrir os mecanismos? Ademais, tal abordagem não reforça a redução da problemática identitária a uma troca entre pesquisador/pesquisado? Se a recusa do etnocentrismo impede que se formule uma definição objetiva da vinculação racial, será, portanto, indispensável investigar os mecanismos utilizados pelos próprios atores quando integram os traços raciais no seu modo de apresentar-se ou de apreender o outro. 


\section{Cartagena, cidade mestiça?}

Em Cartagena, as modificações constitucionais (reconhecimento do multiculturalismo) e a introdução da Lei 70 destinada às "populações afro-colombianas" não provocaram nenhum movimento significativo de reivindicação étnica. Algumas associações e alguns candidatos às eleiçôes bem que tentaram invocar "a negritude", as "comunidades afro-colombianas" ou os "direitos étnicos", mas essas tentativas não surtiram efeito, pois não receberam o apoio da população e mais pareceram um artifício político. ${ }^{1}$ Convém ainda lembrar que a própria Lei 70 torna difícil a instauração de um sistema de discriminação positiva para outra região que não seja a do Pacífico, diretamente afetada pela questão das "terras da Nação" (terras baldias), capítulo principal da lei. Foi assim que, por exemplo, o candidato à prefeitura do Movimiento de las Comunidades Negras só obteve 1,36\% dos votos na eleição local de outubro de 1997, ou que as eleições dos delegados das comunidades negras do Atlântico só se realizaram uma única vez, em 1997. A afirmação de uma especificidade étnica é quase sempre percebida como forma de oportunismo político que instrumentaliza o discurso multicultural, ou como forma de racismo que estigmatiza o mais negro.

Cartagena é, de fato, apresentada como o cartão postal turístico da Colômbia, como um oásis de paz num país mais conhecido pela multiplicidade e recorrência das formas de violência. Tombada pela Unesco, desde 1984, como Patrimônio mundial da humanidade, ela ostenta um passado glorioso e se identifica com o Caribe - e não com o interior andino, considerado conflitual - para valorizar sua tradição de integração e de mestiçagem. Inúmeras evocações de Cartagena póem agora em destaque a miscigenação, considerada como a característica principal da cidade: numa revista distribuída pela sociedade hoteleira internacional Hilton, Cartagena é comparada a uma "jóia racial" que apresenta os cruzamentos entre todas as raças (Garcia Usta, 1988); um artigo sobre a gastronomia da cidade considera-a como o resultado da "decantação, durante anos, da qual participaram raças diversas e várias influências" (Martinez Emiliani, 1991). De modo geral, o fato de associar a cidade ao Caribe, que o escritor Gabriel García Marquez elegeu como cenário para muitos de seus romances e contos, ajuda a reforçar sua imagem de cidade mestiça (García Marquez, 1985). Assim, Cartagena valoriza seu pluralismo racial, com destaque para a origem índia e africana através dos consagrados símbolos da India Catalina e da palenquera, celebrando a diversidade racial das rainhas de beleza locais. Numa das 
maiores agências turísticas de Cartagena, Gema Tours, a justificativa dada para a sobre-representação de guias morenos (eufemismo corrente para a palavra mestiço) é a seguinte: "é uma atração turística. Os morenos são um símbolo. E os morenos daqui não são como os de Nova York. Os de lá metem medo, mas os daqui já são mais miscigenados, têm traços físicos mais suaves. E agradam aos turistas" (entrevista, 11 de outubro de 1998).

De fato, Cartagena foi o porto onde desembarcaram não só os colonos espanhóis e os escravos africanos, mas também os comerciantes sírio-libaneses, os traficantes de todos os horizontes, os piratas europeus. O número de escravos, embora considerável, jamais atingiu a proporção que havia nos outros centros urbanos da época, pois Cartagena era, antes de tudo, lugar de chegada e de trânsito. Em 1778, Jaime Jaramillo Uribe estimava que os escravos em Cartagena representavam $7 \%$ da população da cidade, contra $39 \%$ na região do Chocó, 19\% em Popayán, 18\% em Antioquia e 10\% em Santa Marta (Jaramillo Uribe, 1994: 219-220). Considerava, na mesma época, que a população mestiça constituía $65 \%$ dos habitantes de Cartagena (ibidem:12). Alfonso Munera, ex-diretor da Faculdade de Ciências Humanas da Universidade de Cartagena, considera o aumento da miscigenação como vetor essencial do desenvolvimento da cidade, reinterpretando o principal acontecimento da história de Cartagena - a tentativa frustrada de independência em 11 de novembro de 1811 - como uma revolta de artesãos e pequenos comerciantes contra a dominação dos crioulos de origem européia (Munera, 1998).

No entanto, essa imagem de "cidade mestiça", difundida tanto pelos intelectuais quanto pela imprensa, pelas campanhas turísticas ou pelos próprios habitantes, coexiste com uma representação bem diferente, misto de polarização racial e paternalismo inferiorizante. $\mathrm{Na}$ origem deste segundo discurso sobre Cartagena, encontram-se historiadores pertencentes à elite social e política que mostram os colonos europeus e seus descendentes como os únicos atores da história da cidade. Não só lembram com insistência a origem européia desses colonos, a grandeza de suas intençôes e sua nobreza de costumes, mas, quando se referem às populaçôes negras e mestiças, citam apenas o tráfico e a situação dos escravos, ou as revoltas dos marrons, ${ }^{*}$ os escravos fugidos que se acoitaram nos arredores de Car-

\footnotetext{
* O termo (alteração de cimarron), originário das Antilhas, designa o escravo fugitivo em luta pela liberdade. Não é sinônimo perfeito de quilombola, como pretendem alguns, pois nem sempre o objetivo do marron era formar quilombos. (N. da T.)
} 
tagena (Porras Troconis, 1965; Bossa Herazo, 1967; Bustamante, 1977). Entre evangelização dos escravos domésticos e repressão da ameaça marron, a mestiçagem adota a forma de imposição e de dominação do "branco", assimilando civilização a embranquecimento (cultural e não biológico). Eis porque os quatro volumes da Histoire Générale de Cartagena, de Eduardo Lemaître, que parece ignorar a existência da mestiçagem e só retém uma "perfeita alteridade" (o outro, escravo ou marron), ainda são considerados obra de referência; a maior prova disso é a publicação, com base em seus trabalhos, de um manual destinado aos alunos das escolas da cidade (Funcicar, 1994) ou de um resumo traduzido em inglês e distribuído nos pontos turísticos (Lemaître, 1998).

Essa dupla leitura da história de Cartagena é reveladora das ambigüidades próprias a seu estatuto de "cidade mestiça": pois a mestiçagem, hoje valorizada, tende a ocultar - por trás do mito do híbrido moderno, da fusão e do sincretismo, portador de certa modernidade do indivíduo - a recorrência das diferenciações raciais e dos antagonismos sócio-econômicos; do mesmo modo, sob pretexto de uma apresentação a-racial da história, o discurso da aristocracia contribui para manter a "fronteira da cor" que preserva o grupo dominante.

Porque, apesar dessa imagem, a polarização racial está presente em Cartagena. Compreende-se, aliás, por que Solan e Kraus, dois pesquisadores da linha anglo-saxônica que estuda as relações raciais, caracterizaram a cidade, em seu trabalho pioneiro de 1967 , em termos de "discriminação sem violência", mostrando a mistura paradoxal de discriminação e de integração, característica de Cartagena. A cidade continua dominada por uma elite branca muito fechada que não se cansa de lembrar, por meio de intermináveis árvores genealógicas, a origem européia de seus antepassados; elite que se encontra em lugares exclusivos (bairros, clubes sociais) e cujos sobrenomes compostos (Velez Velez, Benedetti Benedetti, Lelarge Lelarge) atestam a predominância de uma lógica endogâmica. Por outro lado, a aliança com o "negro" constitui um sinal de exclusão, um estigma, uma inferiorização (Streicker, 1992, 1995) que se percebe na linguagem (como o demonstra a expressão "negro tenia que ser") e na vida prática. Exemplo disso é o modo de ver a champeta, música de origem africana (inspirada sobretudo no soukous do Congo) muito popular nos bairros marginais da cidade, e "naturalmente" estigmatizada como violenta, agressiva e transgressora das normas sociais aceitáveis, num processo comparável, 
por várias razões, ao que ocorre com o rap nos Estados Unidos e, em menor proporção, na França.

Portanto, à imagem idílica de uma Cartagena turística, "pérola do Caribe", na qual convivem harmoniosamente populações mestiças, é possível opor-se uma realidade mais complexa. Porque a cidade sofreu profundas transformações desde os anos 1960-1970, passando da categoria de cidade provinciana adormecida sobre o passado glorioso, marginalizada politicamente, para a de metrópole regional, com quase um milhão de habitantes, aberta para a América Latina e o Caribe. À riqueza turística vieram, assim, juntar-se as atividades portuárias e petroquímicas; à oposição centro/periferia, sucedeu um ativismo político que passa pela descentralização e pela implantação na área caribenha. Crescimento demográfico, expansão dos bairros marginais, chegada maciça de refugiados da violência, insuficiência de infra-estrutura urbana, redução da política da cidade a uma política turística: eis algumas das atuais características de Cartagena. Nesse contexto urbano tumultuado, o paternalismo tradicional e a relativa harmonia das relações raciais coexistem com novas formas de vassalagem identitárias e fontes de conflito inéditas.

\section{Chambacú, gueto negro?}

O estudo de Chambacú, bairro "negro" resultante de invasão e hoje desaparecido, mítico desde que o escritor Manuel Zapata Olivella o celebrizou, ajudará a medir a dimensão territorial dos processos de atribuição de status e a examinar as relaçôes entre as identificações sociais, raciais e espaciais. A forte segregação sócio-espacial que caracteriza Cartagena hoje em dia, com a oposição sobretudo dos bairros turísticos e históricos (que são o local de residência das classes favorecidas) ao restante da cidade, é raramente expressa em termos étnicos ou raciais. A essa regra, só há uma exceção, a de Chambacú, antigo bairro de invasão situado ao pé das muralhas (cf. figura 3) que são a encarnação da Cartagena heróica e turística, hoje um vasto terreno baldio sobre o qual pairam inúmeros projetos de urbanização. Não que o bairro seja sistematicamente apresentado como um gueto negro, mas é ele o único a ser pensado, às vezes, em termos étnico-raciais.

Estudar Chambacú corresponde, portanto, por um lado, a melhor compreender os processos de rotulagem - ou de não-rotulagem - étnica através da diversidade das narrativas e, por 
outro lado, a estudar as dinâmicas mútuas da etnicização e da territorialização. Para retomar os termos de Robert E. Park, o estudo de Chambacú sugere o confronto entre ordem moral, domínio da comunicação entre as pessoas, e ordem ecológica, domínio da competição entre populações diferentes. A ordem moral, que regula o campo das interações de indivíduos, é inseparável de sua inscrição numa ordem ecológica que contribui para a significação das categorias.

A noção de gueto -e, além dela, a de bairro étnico- foi objeto de muitas discussões sobre sua associação "natural" com a etnicidade, sobretudo nos Estados Unidos, país que o erigiu em paradigma sociológico. Vamos considerar um aspecto dessas discussóes, o da diluição da dimensão racial do gueto, que acabaria por designar "um espaço urbano de pobreza extensa e intensa, que oculta o fundamento e o caráter racial dessa pobreza". ' (Wacquant, 1997:341). A questão do caráter racial do gueto surge de fato nos Estados Unidos desde que várias pesquisas (Foreman, 1971; Jencks \& Peterson, 1991; Wilson, 1991; Jargowsky, 1997) insistiram na dimensão sócio-econômica, deixando entre parênteses seu caráter étnico-racial e/ou cultural, tal como ele aparece na definição original do gueto judeu na Europa e, depois, do gueto negro nos Estados Unidos. Será que o gueto se define prioritariamente por sua dimensão étnico-racial? Ou será ele o resultado de um processo de exclusão sócio-econômica? Pode-se falar de "gueto branco"? Deve-se dar prioridade a um ou a outro desses fatores? Como isolar um do outro? Deve-se propor uma definição a priori ou tomar como base uma caracterização empírica? Qual o papel do pesquisador na definição do "gueto étnico"? E o papel dos próprios atores? É a composição da população que faz com que um bairro seja étnico? Ou essa etnicidade será o resultado de um processo de rotulagem e de uma territorialização especial? De certa maneira, a reflexão sobre o gueto só admite, no caso, territórios e identidades pré-fabricados ${ }^{3}$ como garantia de validade epistemológica para Loïc Wacquant, ou como fatores independentes para os autores norte-americanos. Interesso-me, porém, pelos mecanismos de racialização das relações sociais, nos quais a relação com o espaço não é produto nem causa, mas sim recurso e imposição para os atores. O que as reflexões sobre o gueto esquecem é o ponto de vista do indivíduo sobre a cidade e sobre si mesmo, o ponto de vista de um sujeito que institui um objeto e, em retorno, é instituído como sujeito (Lepetit, 1996). "É o que aqui nos interessa: não se trata de estabelecer a identidade de um espaço fazendo a genealogia de sua sin- 
gularidade, mas sim de analisar as diferentes relações que existem entre a idéia que as pessoas têm do espaço e a idéia que elas têm de si mesmas ou dos outros (Monnet, 2000: 20).

Chambacú, no fim do século XIX, não passa de um emaranhado de mangues-vermelhos, entre terra e mar: os inúmeros ataques que marcaram a história de Cartagena obrigam a população a viver dentro das muralhas. Em Chambacú existem algumas cabanas de madeira de propriedade dos moradores da cidade que vivem intramuros, ou casebres que servem de abrigo para os visitantes que não conseguem entrar no recinto fortificado, pois suas portas se fecham diariamente ao pôr-do-sol. Desse modo, no Registro de notarios dos Arquivos Históricos de Cartagena só consta uma casa em 1881. Depois, Chambacú começa a povoar-se com a chegada da ferrovia, no início do século XX. As primeiras construções da ferrovia provocam uma migração de mão-de-obra proveniente das aldeias vizinhas, que se instala naturalmente ao pé das muralhas, entre a cidade e a aldeia de origem, e também no ponto de partida da via férrea. Na mesma época, do outro lado da cidade, o traçado da avenida Santander, entre o mar e as muralhas, provoca a destruição dos bairros Pekin, Pueblo Nuevo, El Boquetillo, cujos moradores, em boa parte, vão procurar abrigo em Chambacú. Ora, esses três bairros, encostados nas muralhas, onde moravam os antigos escravos, tornaram-se, após a abolição em 1851, bairros de empregados domésticos, jardineiros e artesãos em geral.

Depois de 1815 , com a violenta repressão à primeira independência da cidade, que levou à eliminação de sua elite política e à destruição de seu potencial econômico, Cartagena entrou numa longa fase de letargia, passando da posição de porto independente e próspero, voltado para o Caribe, à de cidade provinciana, marginalizada em nível nacional, e, em nível local, ultrapassada pelo dinamismo da rival Barranquilla. A partir dos anos 1960, Cartagena retoma seu passado glorioso, apresentado a partir de então sob a forma de um patrimônio nacional e internacional, e como atração turística entra num novo ciclo de prosperidade. Chambacú já não combinava com a imagem dessa cidade que se pretendia organizada e desenvolvida, moderna e turística. É o Instituto de Crédito Territorial-ICT, órgão nacional responsável pela política de habitação social, que está na origem da erradicação de Chambacú no início dos anos 1970. Hoje, quase trinta anos depois, nenhum dos diversos programas de urbanismo propostos para justificar tal operação (construção de um bairro de classe média, inauguração de um novo centro administrativo, criação de um centro comercial, projeto de marina de luxo) foi instalado: Chambacú permanece um 
imenso terreno baldio que separa o centro do resto da cidade e evidencia, de modo incômodo e penoso, as ambiçôes e impasses da nova política urbana instaurada desde os anos 1960. Projetos destinados a utilizar esse terreno situado a poucos metros do centro histórico, ao pé das muralhas, não faltam. Recentemente, o terreno foi vendido à firma Chambacú de Indias S. A., e a ganância despertada por sua localização provocou um escândalo político-financeiro que implica altos funcionários, entre os quais o ministro do Desarrollo Económico e o embaixador da Colômbia em Washington, acusados de tráfico de influências, desvio de recursos públicos e desaparecimento de documentos administrativos.

Como os diferentes atores e observadores do "episódio Chambacú" apresentam e justificam a supressão desse bairro? Os termos utilizados são bem reveladores: enquanto uns se referem à "erradicação" do bairro como um processo violento e indesejado, outros falam de "remoção", apresentando o mesmo fenômeno, num eufemismo, como positivo. Se essa dupla interpretação do processo de "limpeza" dos bairros de invasão já é clássica na Colômbia e alhures, vou focalizar aqui mais precisamente a racialização diferencial dessas apresentações, entre supressão de qualquer referência étnico-racial nos discursos oficiais e destaque da lógica racial nos textos artísticos.

Para a atual diretora do Inurbe - Instituto Nacional de Interesse Social e de Reforma Urbana, herdeiro do Instituto de Crédito Territorial, a remoção dos moradores de Chambacú se interpreta sobretudo em termos de acessão à citadinidade.

Era um tugurio (favela), sem nenhum serviço público, com eletricidade pirateada, e com moradores que não pagavam nenhuma taxa pública. Havia uma forte decomposição social, nem se podia passar por perto. Nos novos bairros, foram-lhes entregues casas, casas de verdade, com todos os serviços, água, eletricidade. (entrevista, 16 de setembro de 1999)

Do mesmo modo, o arquiteto que participou da construção das novas moradias para os habitantes de Chambacú enfatiza a dimensão social do projeto:

em Chambacú todo mundo construía sua casa com um pedaço de papelão, com um telhado de papelão, com qualquer coisa. Em pleno coração $\mathrm{da}$ cidade, encostado às muralhas, por trás da India Catalina, as pessoas paravam e viam aquela coisa. Colaborei muito para erradicar esse bairro porque, em Cartagena, não havia casas para os pobres. E nós começamos a fazer moradias, para as quais as pessoas iam chegando pouco a pouco. (entrevista, 3 de agosto de 1999) 
Mas, ao lado desses discursos em que toda dimensão racial está excluída, Chambacú também é apresentado como símbolo da história africana de Cartagena, desde que Manuel Zapata Olivella o tornou conhecido em seu livro Chambacú corral de negros: a análise em termos de promoção social e de renovação urbana é substituída por uma evocação da dimensão racial do fato. O escritor pertence a uma das famílias de destaque na cidade por sua ação em favor do reconhecimento da plurietnicidade e da herança africana de Cartagena: seu irmão Juan, poeta e médico, foi o primeiro candidato negro a uma eleição presidencial; sua irmã Delia foi pioneira em matéria de estudo e divulgação do folclore afro-colombiano. Quanto a Manuel, por muito tempo embaixador da Colômbia, é o autor de muitos romances e ensaios que tratam da epopéia das populações negras: Chango, el Gran Putas; Levantate Mulato. Por mi raza hablará el espiritu; Las claves mágicas de América. Em Chambacú corral de negros, Manuel Zapata Olivella evoca a história do bairro. Em algumas palavras, pronunciadas por Máximo, personagem central do romance, a situação é apresentada:

A ilha está crescendo. Amanhã seremos quinze mil famílias. O 'Câncer negro', como eles nos chamam. Querem destruir-nos. Têm medo de que um dia atravessemos a ponte e a onda de favelas inunde a cidade. Por isso é que para nós não há ruas, nem esgoto, nem escolas, nem saúde. Querem afundar-nos na miséria. Estão enganados. Vamos lutar por nossa dignidade de seres humanos. Não vamos deixar que nos expulsem de Chambacú. Eles não hão de mudar a face negra de Cartagena. Sua grandeza e glória apóiam-se nos ossos de nossos antepassados. (Zapata Olivella, 1990a:199)

Recentemente, Chambacú foi igualmente glorificada por outra artista, considerada também porta-voz da cultura afro-colombiana: a cantora Totó La Momposina, uma das mais célebres vozes do Caribe colombiano, que dedica em seu último $\mathrm{CD}^{4}$ duas canções ao bairro hoje transformado em terreno baldio. A primeira, "Chambacú", fala do cotidiano de uma negrinha e da história desse bairro de "negros Bembé"; na segunda, a intérprete conta:

"En el barrio 'e Chambacú

fui a visitar una familia,

Ay de origen Bantú (...)

Oh, Chambacú, sudor de negros

historia de esclavos".
"No bairro de Chambacú

fui visitar uma família,

$\mathrm{Ai}$, de origem banto (...)

Ó, Chambacú, suor de negros

história de escravos". 
O bairro torna-se um episódio central da história de Cartagena, a encarnação do destino reservado às populações negras, de sua marginalização e segregação.

"Chambacú, Chambacú, Chambacú... "Chambacú, Chambacú, Chambacú...

La historia de las murallas

A história das muralhas

con sangre la escribió la canalla,

com sangue a escreveu a ralé,

con sangre la escribió la canalla,

com sangue a escreveu a ralé,

con la pluma del dolor,

com a pena da dor,

con la pluma del dolor,

curando la carne esclava

com a pena da dor,

curtindo a carne escrava

a lo lejos se ve la muralla,

ao longe se vê a muralha,

a San Pedro Claver con la saya,

São Pedro Claver com a batina,

curando al negro Bembé,

curtindo o negro Bembê,

curando al negro Bembé,

curtindo o negro Bembê,

Chambacú, Chambacú,

Chambacú, Chambacú,

Chambacú, Chambaculero

Chambacú, Chambaculero,

De aquí no me sacas tú

Daqui não me tiras

Chambacú, Chambacú, Chambacú... Chambacú, Chambacú, Chambacú...

la historia la escribes tú”.

a história é escrita por ti".

Gueto étnico, favela sócio-econômica: a identificação é também uma questão de rotulagem e remete à posição e aos interesses de quem a enuncia. Para uns, Chambacú devia ser eliminada a fim de melhorar as condiçôes de vida de seus moradores; para outros, a destruição de Chambacú decorre de uma lógica de segregação racial numa cidade que procura melhorar a própria imagem. Para uns, a dimensão sócio-econômica é o principal fator de explicação da história de Chambacú; para outros, só a dimensão racial é levada em conta. Mas, num como noutro caso, tudo acontece como se as identidades pré-definidas viessem encarnar-se num território ao qual seriam imediatamente atribuídas as características próprias a essa identidade. Para Manuel Zapata Olivella, por ser Chambacú um "câncer negro" é que não possui ruas, nem esgoto, nem escolas, nem saúde; por ser a população de Chambacú negra é que ela não tem acesso a uma vida urbana efetiva. Esse raciocínio tem um paralelo simétrico nas interpretações sócio-econômicas: porque a população de Chambacú não conta com infra-estruturas públicas é que ela é considerada negra, o acesso à vida urbana transformando-se em sinônimo de embranquecimento. Prova disso é o trecho de um artigo do Magazin Dominicalque resume, de modo lapidar, a destruição de Chambacú: 
um dia pensou-se que Deus fizera um milagre quando alguns negrinhos de Chambacú subiram num daqueles ônibus desmantelados da época, atravessaram algumas ruelas típicas e chegaram ao seu destino bem arrumadinhos e quase brancos. (ElEspectador, Magazin Dominical, 11 de novembro de 1973)

A uma população pobre corresponderia, assim, a favela ou tugurio; a uma população negra, o gueto étnico. Essas assimilações apresentadas como naturais evitam a questão da identificação dos indivíduos e dos territórios. Baseiam-se num duplo pressuposto: por um lado, existiriam territórios e identidades definidos de modo independente uns dos outros; por outro lado, haveria uma perfeita correspondência (objetiva e subjetiva) entre essas identidades e esses territórios. Convém, ao contrário, colocar-se num ponto médio entre essas duas posições, na interação do social com o espacial: os indivíduos "escurecem" quando associados a um bairro; um bairro vira gueto em função dos moradores que nele habitam. Esses processos são não só dinâmicos e relacionais, mas a adequação entre lógica espacial e lógica identitária está longe de ser sistemática.

\section{Movimentos Marrons identitários e territoriais}

Quem se coloca no cerne dos processos de identificação sócio-espacial precisa focalizar não as identidades e os territórios, nem as práticas subjetivas e sua encarnação espacial, estudados de modo independente e sucessivo, mas sim suas interações, seus mecanismos de construção recíproca. É, portanto, da própria situação que se vai partir, o que permite, em termos de Goffman, explicar os mecanismos de acoplamento, impreciso e múltiplo, entre ordem estrutural e ordem das interaçóes, estudar a capacidade que têm os indivíduos de avaliar seu meio tanto social quanto espacial, de definir simultaneamente o outro e seu território, Nesse quadro, as aparências raciais surgem como um "marcador de identidade" (Jean-Luc Bonniol), um "discriminante do papel” (Ulf Hannerz), uma imposição externa ao levantamento dos papéis, ao conjunto dos compromissos individuais. Ao estudar duas formas de movimentos marrons contemporâneos, tenta-se compreender como os mecanismos de gestão social das aparências raciais são reveladores dos modos diferenciais de produção de normas sociais e de construção do espaço.

É importante estudar a cidade de Cartagena pois ela tem uma minoria, os palenqueros, ${ }^{5}$ que corresponde diretamente à lógi- 
ca instaurada pelo reconhecimento do multiculturalismo (com mais precisão, deve-se falar não de palenqueros em geral, mas de uma fração deles, culta, em plena ascensão social e que pretende representá-los). Sua ação como marron, entendida no sentido histórico original do termo, mais parece um distanciamento, tanto espacial quanto identitário. No contexto atual, assume a forma de uma transformação do estigma social em valorização étnica. Ao instrumentalizar seu passado de cimarrones, ao apropriar-se do mito de Benkos Bioho, ${ }^{6}$ ao enfatizar sua especificidade cultural (língua, práticas religiosas, organização social), os palenquerossão hoje, em Cartagena e no litoral caribenho colombiano, os únicos representantes dessa "etnia negra" à qual novos direitos (mínimos) são concedidos. Porque esse processo de construção de um ator étnico numa nova paisagem multicultural passa também pela exclusão dos que não podem exibir a nova identidade negra, isto é, a quase totalidade dos habitantes de Cartagena, que não se reconhece no discurso palenquero.

Os "empresários étnicos" palenqueros confrontaram-se com a experiência urbana: foi do encontro com o outro e da aprendizagem de um modo de vida caracterizado por relações múltiplas e parciais que nasceu a afirmação de sua especificidade cultural. Mas essa experiência do pluralismo e da fluidez das identificações permite a construção de um território mítico, a aldeia de Palenque de San Basilio, terra africana da região Atlântica, suficientemente subjetivo para ser considerado como um recurso mobilizável, suficientemente objetivo para legitimar a emergência de um ator étnico. A referência a esse território imaginário funciona então como um recurso mobilizado no processo de construção identitária e contribui para a formação de uma "identidade étnica", tal como a reivindicam os líderes de Cartagena - à sua conformação, pode-se dizer - pois os mecanismos de identificação e de territorialização se fortalecem mutuamente. Porque a evocação da aldeia imaginária, último bastião da autenticidade africana, autoriza a construção de uma comunidade, também ela imaginária, guardiã de uma cultura africana preservada; ao mesmo tempo, o reconhecimento local e nacional do discurso étnico palenquero transforma Palenque de San Basilio em museu vivo da africanidade. Ambos os processos, longe de serem independentes, se reforçam mutuamente.

De certo modo, é toda a população de Cartagena que fica duplamente discriminada pela emergência dessa nova barreira étnica: primeiro, por sua exclusão da cidadania efetiva e, segundo, por sua exclusão do direito à diferença. Primeiro, porque ela é ne- 
gra; segundo, porque ela não é suficientemente negra. Mais ainda: a associação do princípio democrático de igualdade com a afirmação recente do multiculturalismo priva a maioria da população de qualquer possibilidade de reivindicação identitária. Logo, o paradoxo: o semi-sucesso do igualitarismo republicano explica o semifracasso da discriminação positiva. Pois a obsessão da diferença, a instrumentalização do multiculturalismo e a afirmação da etnicidade produzem também a exclusão de quem não pode valer-se da identidade dada como exemplo. De Palenque de San Basilio ao Caribe, o multiculturalismo se expressa sob os traços da objetivação e da diferença absoluta, por um lado, e da imprecisão e da diferença relacional, por outro lado; da imposição de um modelo identitário, por um lado, da negociação situacional, por outro.

As atuais celebrações do cabildo atualizam uma tradição de luta marron menos conhecida (por ser menos violenta e menos visível) que não assume a forma de apropriação comunitária do espaço urbano, nem a de citadinidade desencarnada. Os cabildos eram, na época colonial, espaços reservados aos escravos que, durante um dia, deixavam o trabalho, vestiam a roupa dos senhores, divertiam-se, escutavam a música de seus donos, dançavam à vontade, praticavam seus cultos religiosos. Em Cartagena os cabildos mais importantes ocorriam em 2 de fevereiro, pela festa da Virgem da Candelária, a padroeira de Cartagena. Na metade dos anos 1980, um grupo de moradores de Getsemaní, bairro considerado como dos escravos e dos artesãos mulatos, decide reavivar a tradição dos cabildos e para isso organiza desfiles e espetáculos. Nasce assim o Cabildo de Getsemaní, que adapta um pouco a história e escolhe 11 de novembro como data das comemorações. Transformada em festa republicana, com certa reapropriação da herança das lutas pela independência e com a lembrança do papel desempenhado pelos habitantes de Getsemaní, tendo à frente Pedro Romero e os Lanceros de Getsemaní, o Cabildo aproveita assim o contexto festivo e mediático das comemorações de 11 de novembro, em torno, principalmente, dos concursos de beleza. Mais ainda: pretende reativar nessas festas de novembro o aspecto popular e a autenticidade perdidos com a predominância do Concurso Nacional de Beleza e da imposição de interesses externos. Formado por quarenta grupos em 1998, o Cabildo desfilou pelo Paseo Bolivar, um dos mais importantes eixos de comunicação de Cartagena, até chegar a Getsemaní. Depois de ter reverenciado o deus ioruba Oiá, ele festeja este ano La Ceiba, árvore por meio da qual os orixás se comunicam com 
os homens, apresentada como duplo símbolo da América e da África, por Nilda, rainha do Cabildo.

O Cabildo foi o momento em que se fez um trabalho de compilação de histórias orais dos moradores do bairro de Getsemaní e de pesquisas sobre as tradições festivas e religiosas da cidade; esse trabalho começou na associação Gimani Cultural, nascida em 1986, e foi depois mantido pelo Fondo Mixto de Cultura de Cartagena (dependente do Ministério da Cultura), organismo público à frente do qual está Nilda, rainha do Cabildo de Getsemaní. Em 1998, o folheto de apresentação do Cabildo descreve as diferentes danças, destacando sua origem africana (Danza de los Macheteros, Danza del Garabato, Danza del Congo, Danza de los Diablos) e reescreve a história dos habitantes de Cartagena, nem apenas escravos impotentes, nem também marrons em luta: "A realização dessas festas alegres e coloridas era uma necessidade para os negros que, trazidos da África como escravos para trabalhar na construção das casas, igrejas e fortificaçôes da cidade e nas casas e fazendas dos grandes proprietários, conservavam suas próprias manifestações culturais, entre elas o culto a seus deuses, sempre acompanhado de cânticos, danças, fantasias e batida de tambores".

A reapropriação da história acompanha um programa de educação, de participação cidadã, de construção da citadinidade que se encarna no projeto de Gimaní Cultural. Porque, no meio dos anos 1980, quando nascem simultaneamente o Cabildo e a associação Gimaní, Getsemaní é um bairro devastado, cuja decadência econômica, social e até arquitetônica torna-se mais visível porquanto o resto da cidade histórica passa por uma reabilitação e por um dinamismo ligados ao desenvolvimento turístico e à chegada de novos moradores. Considerado como um bairro popular e marginal situado dentro das muralhas, por oposição, por exemplo, ao aristocrático bairro de San Diego, centro do comércio e do contrabando, sede do mercado desde 1974, Getsemaní foi o bairro dos aventureiros estrangeiros, dos comerciantes judeus, mas sobretudo dos mulatos independentes, dos escravos forros, das empregadas domésticas negras. Esquecido pelas políticas urbanas, abandonado pelos projetos de desenvolvimento turístico, afetado pela crise econômica, Getsemaní tornou-se um bairro marginal e perigoso, ponto de prostituição e de tráfico de drogas, marcado pela violência e cuja decadência é materialmente simbolizada pelas construçôes coloniais e republicanas se desfazendo em ruínas. Ora, no projeto da associação Gimani Cultural, a recusa da estigmatização racial e do declínio socioeconômico se conjugam para dar origem a 
uma verdadeira proposta política de reinvestimento da cidade. A partir da organização de eventos "cívico-culturais", trata-se de estimular uma participação cidadã que passa pela recuperação e pelo desenvolvimento de "valores cívicos festivos na cidade" (programa da Fundación Gimaní Cultural, 1997:4).

Para Nilda, que quer transformar os desfiles do Cabildo em carnaval, a valorização da herança africana não significa concentração comunitária, encarnada pelo exemplo dos palenqueros, mas incita, ao contrário, a uma abertura para a participação popular, em que a identificação racial assume a forma de referência ao Caribe:

Fomos buscar a tradição africana em Bocachica que, por ser uma ilha, permaneceu mais isolada e manteve sua autenticidade. Mas não é como os palenqueros. Estes querem conservar a pureza de sua raça, não se misturam. Perto de La Popa, há palenques urbanos, muito fechados. Somos mais abertos. Para nós, a cidade é a esquina da rua, e a esquina é o Caribe, com todas as suas misturas. Os palenqueros dizem que são negros e querem coisas. O Cabildo é como uma Assembléia de Ação Comunal (Junta de Acción Comunal), tem um significado político. Mas não dessa política dos politiqueiros. Queremos envolver toda a cidade, que seja um espaço de participação. O Cabildoé o canal de expressão de um povo caribenho. Cartagena é a única cidade onde não é preciso afirmar-se caribenho, para sê-lo. (entrevista, 7 de janeiro de 1998)

Em 23 e 24 de setembro de 1999, a associação Gimani Culturale o jornal El Universal organizaram o Primeiro Simpósio sobre o Pensamento Popular e a Cultura Festiva de Cartagena. A finalidade era fazer o balanço de dez anos de Cabildo, refletir sobre os objetivos e a contribuição da criação de um carnaval e, de forma mais ampla, favorecer os debates sobre a cultura popular, a herança africana, a participação política, o desenvolvimento da citadinidade. Nilda relata essa tomada de posse da cidade que acompanha o nascimento e o desenvolvimento do Cabildo:

O Cabildo vem de Getsemaní com esta pergunta: como recuperar nosso bairro para nosso uso e nossa satisfação? A cidade expressou-se através do Cabildo que corresponde também a um trabalho cívico do qual participa toda a comunidade. Mais do que recriar o Cabildo, a idéia é recriar a identidade da cidade e desenvolver uma cultura cidadã. Em dez anos fizemos germinar no coração dos habitantes de Cartagena a idéia de organizar um carnaval. Isto é, contar com um princípio cidadão suficientemente popular para 
que essa grande manifestação seja possível com a participação de todos. O centro histórico converteu-se em mausoléu. O morador de Cartagena já não vive no centro. A única resistência é a de Getsemaní. É preciso recuperar o que nos pertence por meio das tradições festivas. O Paseo Bolivaré o local do Cabildo. O Cabildo segue o deslocamento da cidade quando ela deixa o centro, as muralhas. Estamos conscientes de que a cidade começa a partir do mar. Estamos num processo cidadão, de construção do lugar e da cidade onde vivemos.

\section{Conclusão}

A relação com aquele que é diferente não é um caso particular ou extraordinário; ela faz parte das interações cotidianas comuns, é a encarnação da questão do vínculo democrático (Martucelli, 1999: 447), revela as virtudes próprias à entrada na urbanidade e na citadinidade. A cidade, porque obriga ao confronto e à coexistência num mesmo território, explica mecanismos que existem na identificação de si e do outro; ao mesmo tempo, a gestão cotidiana da diferença participa da produção de espaços urbanos, num movimento de vaivém entre identificação e territorialização. "Toda sistematização do princípio de discriminação positiva que tenda a estabelecer que um espaço justo é o espaço apropriado acaba por negar dois fundamentos da cidade e da urbanidade: a co-presença e suas conseqüências (as duas formas do direito de visita - a intrusão e o senso comum) e a mobilidade" (Joseph, 1995: 35). Mais que um fracasso, o fraco desenvolvimento do multiculturalismo em Cartagena pode ser tomado como a conseqüência da pregnância de processos de identificação situacionais e interacionais, por meio dos quais seus habitantes constroem simultaneamente seu direito à citadinidade e seu direito à diferença. Ao qualificar em situação os passantes e seu entorno, transformam o controle do face a face com o outro numa forma de testar o vínculo democrático em escala microssocial, e numa etapa para a reivindicação cidadã.

\section{NOTAS}

1. Os candidatos negros fizeram mútuas acusaçôes de oportunismo eleitoral, e um deles até preferiu inscrever-se numa lista índia, por considerar que estas reivindicaçôes étnicas eram mais "autênticas". 
2. Wacquant também critica a idéia segundo a qual o gueto é desorganizado, ou a tendência a só se ver nele o aspecto exótico.

3. É aceita, como um dos elementos constitutivos da noção de segregação, a idéia de fronteiras espaciais que separam grupos bem identificados (Brun \& Rhein, 1994:37).

4. Totó la Momposina, Pacantó, MTM Ltda., 1999.

5. Habitantes de Palenque de San Basilio, aldeia de negros marrons a alguns quilômetros de Cartagena, hoje apresentada como "a primeira aldeia livre da América", conseqüência de um acordo de não-agressão mútua, firmado entre a coroa espanhola e os moradores locais em 1713 (Arrazola, 1970).

6. Rei africano que teria chefiado as revoltas de escravos e fundado Palenque de San Basilio.

7. Apresentação do Cabildo 1998 à imprensa, no restaurante La Carbonera, em 22 de outubro de 1998.

\section{Referências Bibliográficas}

ABU-LUGHOD, Janet (1997). "The specificity of the Chicago Ghetto: comment on Wacquant's 'Three pernicious premises'”. International Journal of Urban and Regional Research, vol. 21, $\mathrm{n}^{\circ}$ 2, juin, pp. 357-362.

ALVAREZ MARIN, Moisés (1990). "La historiografía Cartagenera”. Cuadernos de Historia, $4^{\text {ìme }}$ année, $\mathrm{n}^{\circ}$ 2, juin-décembre, pp. 5-14.

ARRAZOLA, Roberto (1970). Palenque, primer pueblo libre de América. Cartagena, Editorial Hernandez.

BOSSA HERAZO, Donaldo (1967). Cartagena independiente: tradición y desarrollo. Bogotá, Ediciones Tercer Mundo.

De BUSTAMENTE, Francis (1977). Cartagena de Indias. Ciudad heroica. Historial de 1533 a 1830, Cartagena, Editorial Bolívar.

CALVO STEVENSON, Haroldo, MEISEL ROCA, Adolfo (eds.) (1998). Cartagena de Indias y su historia, Bogotá, Universidad Jorge Tadeo Lozano Seccional del Caribe Banco de la República.

CONDE CALDERON, Jorge (1996). "Castas y conflictos en la provincia de Cartagena del Nuevo Reino de Granada a finales del siglo XVIII”. Historia y Sociedad, nº 3, décembre, pp. 83-101.

FOREMAN, R. E. (1971). Black ghettos, white ghettos, and slums. Prentice Hall, NJ, Englewood Cliffs.

FRAZIER, E. Franklin (1949). The Negro in the United States. New York, The MacMillan Company.

FUNCICAR, ALCALDIA MAYOR de CARTAGENA de INDIAS, SECRETARIA de EDUCACION DISTRITAL (1994). Historia de Cartagena de Indias. Primer concurso de historia de Cartagena. Premio Eduardo Lemaitre, textos de Eduardo Lemaitre, desenhos de Javier Covo Torres. Cartagena, Tiempo Editores.

GANS, Herbert J. (1966). The urban villagers: group and class in the life of Italian-Americans. New York, Free Press/London, Collier-Macmillan. 


\section{Elisabeth Cunin}

GARCIA MARQUEZ, Gabriel (1985). El amor en los tiempos del colera. Bogotá, Editorial La Oveja Negra.

GARCIA USTA, Jorge (1988). "El portal de los dulces. Donde Cartagena es una gran familia”. Hilton Colombia, $\mathrm{n}^{-}$7, jan.-mar., pp. 33-35.

GILARD, Jacques (1988). Veinte y cuarenta anos de algo peor que la soledad. Bogotá, Centro Cultural Colombiano.

JARAMILLO URIBE, Jaime (1994). Ensayos de historia social. Tomo 1. La sociedad neogranadina. Bogotá, Tercer Mundo Editores - Ediciones Uniandes.

JARGOWSKY, Paul A. (1998). "Response to Loïc J. D. Wacquant's 'Three pernicious premises in the study of the American ghetto'”. International Journal of Urban and Regional Research, vol. 22, nำ pp. 160-163.

JENCKS, C. \& PETERSON, P. E. (eds.) (1991). The urban underclass. Washington, D. C., The Brookings Institution.

JOSEPH, Isaac (1995). "Reprendre la rue". In Colloque de Cerisy (textes réunis par I. Joseph), Espace public et culture dramaturgique, Paris, Editions Recherches — Plan Urbain, pp. 11-35.

LEMÂITRE, Eduardo (1983). Historia general de Cartagena (quatro volumes). Bogotá, Banco de la República. (1998). Breve historia de Cartagena (3. edição). Bogotá, Medellín, Editorial Colina.

LEPETIT, B. (1996). "La ville: cadre, objet, sujet". Enquête, nº 4, segundo semestre, pp. 11-34.

LEWIS, Oscar, 1991, Les enfants de Sánchez: autobiographie d'une famille mexicaine. Paris, Gallimard.

MARTINEZ EMILIANI, Vicente (1991). "Variaciones sobre el fogon cartagenero". Credencial, n 60, novembro, pp. 80-82.

MARTUCCELLI, Danilo (1999). Sociologies de la modernité. Paris: Folio Essais.

MOSQUERA, Claudia \& PROVENSAL, Marion (2000). "Construcción de identidad caribeña popular en Cartagena de Indias a través de la música y el baile de champeta”. A ser publicado em Aguaita, nº 3 .

MUNERA, Alfonso (1998). El fracaso de la nación. Región, clase y raza en el Caribe colombiano (1717-1810), Bogotá, Banco de la República - El Ancora Editores.

PORRAS TROCONIS, Gabriel (1954). Cartagena hispánica. 1533 a 1810. Bogotá, Biblioteca de Autores Colombianos - Editorial Cosmos.

_ (1965). La Magna Epopeya de Cartagena. El sitio del año 1815. Bogotá, Editorial Temis.

SOLANO, Sergio P. (1998). "Un siglo de ausencia: la historiografía de Cartagena en el siglo XIX". In H. Calvo Stevenson \& A. Meisel Roca (eds.), Cartagena de Indias y su historia. Bogotá, Universidad Jorge Tadeo Lozano-Banco de la República, pp. 217-232.

SOLAUN, Mauricio \& KRONUS, Sidney (1973). Discrimination without violence. Miscegenation and racial conflict in Latin América. New York/London/Sidney/Toronto: John Wiley and Sons.

STREICKER, Joel (1992) Sentiment and self-interest: constructing class and gender identities in Cartagena, Colômbia. Ph. D., Stanford University. 
_ (1995). "Policing boundaries: race, class, and gender in Cartagena, Colombia". American Ethnologist, vol. 22, $\mathrm{n}^{\circ}$ 1, pp. 54-74.

WACQUANT, Loïc J. D. (1997). "Three pernicious premises in the study of the American ghetto". International Journal of Urban and Regional Research, vol. 21, nº 2, junho, pp. 341-353.

WHYTE, William Foote (1995 [1943]). Street corner society. La structure sociale d'un quartier italo-américain, Paris, Editions la Découverte.

WILSON, William J. (1978). The declining significance of race. Blacks and changing American Institutions, Chicago/London, The University of Chicago Press.

_ (ed.) (1993). The ghetto underclass: social science perspectives. London, Newbury Park, Sage.

WIRTH, Louis (1946 [1928]). The ghetto. Chicago, University of Chicago Press.

ZAPATA OLIVELLA, Juan (1985). Mundo poético. Dinámica de la nueva poesía multirracial. Bogotá, Editorial Grancolombia.

_ (1987). "El 11 de noviembre. Añoranza del viejo carnaval”. Hilton Colombia, nº 6, out.-dez., pp. 44-45.

(1989). Las claves mágicas de América. Bogotá, Plaza \& Janés Editores.

(1990a [1962]). Chambacú. Corral de negros. Bogotá, Rei Andes.

(1990b). Levántate Mulato! Por mi raza hablará el espiritu. Bogotá, Rey Andes. 